\title{
Sociedade mundial de risco: teoria, críticas e desafios
}

ESTEVÃO BOSGO

LEILA FERREIBA*

\section{Resumo}

O artigo delineia contradições internas, insuficiências teóricas, inovações e desafios colocados para a sociologia pela teoria da sociedade mundial de risco, formulada por Ulrich Beck. Para tanto, orientamo-nos por uma breve reconstrução da história dessa teoria, situando algumas de suas principais inovações. Em seguida, voltamo-nos para duas críticas consolidadas, nomeadamente a crítica à sua fundação histórico-lógica no cosmopolitismo e a crítica epistêmica formulada por teóricos sociais pós-coloniais. Num terceiro momento, a estratégia metodológica da reconstrução nos permite identificar uma contradição interna entre a fundação da referida teoria no cosmopolitismo metodológico e o diagnóstico dos riscos globais, tendo em vista a tipologia à que este último dá forma. E finalmente, formulamos algumas observações críticas, apontamos alguns desafios colocados para a sociologia e sugerimos reorientações de suas perguntas-chave a partir das críticas mencionadas e da intuição teórico-empírica de uma hermenêutica do risco, da reflexividade e da cosmopolitização ainda por fazer.

Palavras-chave: Sociedade mundial de risco. Cosmopolitismo Metodológico. Beck, Ulrich (1944-2015).

\footnotetext{
* Fundação de Amparo à Pesquisa do Estado de São Paulo (FAPESP), Brasil.

** Universidade Estadual de Campinas (UNICAMP), Brasil.
} 


\title{
World risk society: theory, criticisms and challenges.
}

\begin{abstract}
The article outlines internal contradictions, theoretical insufficiencies, innovations and challenges raised by Ulrich's Beck theory of world risk society for sociology. Therefore, we perform a brief reconstruction of the history of that theory, indicating some of its main innovations. Then we address two consolidated criticisms, namely the criticism of its historical and logical foundation in cosmopolitanism and the epistemic criticism by postcolonial social theorists. Then, our methodological strategy of reconstruction allows us to identify an internal contradiction between the foundation of that theory in methodological cosmopolitanism and the diagnosis of global risks, in view of the typology to which this diagnosis gives form. And finally, we formulate some critical considerations, point out some challenges left to sociology and suggest a re-orientation of the theory key questions, considering the mentioned criticisms and outlining a theoretical and empirical intuition of a hermeneutics of risk, reflexivity and cosmopolitization yet to be done.

Key-words: World risk society. Methodological Cosmopolitanism. Beck, Ulrich (1944-2015).
\end{abstract}

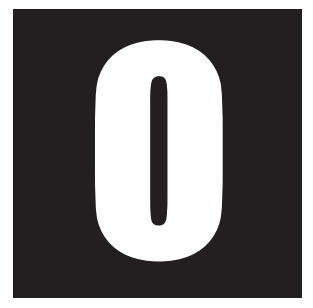

que caracteriza, nos dias atuais, a condição globalizada da vida social? Ulrich Beck talvez tenha sido o pioneiro em fornecer uma resposta propriamente sociológica a essa pergunta, com o seu amplamente debatido Risikogesellschaft: auf dem Weg in ein andere Moderne, publicado em 1986 (2001). Combinando aspectos ambientais e institucionais com uma crítica da racionalidade científica e da modernização, esse livro pode ser tido como uma análise da globalização avant la lettre. Desde então, Beck logrou inserir no vocabulário de uma teoria social globalizada os termos risco, incerteza, meio ambiente e mudanças ambientais, terrorismo, cosmopolitismo e uma concepção de reflexividade vinculada às 
instituições modernas. O conjunto forneceu um aparato teórico e metodológico que esteve em medida de iluminar aspectos da globalização em que essa se manifesta como práxis. A partir dos anos 1990, seus estudos vieram a influenciar pesquisas em áreas muito diversas ${ }^{1}$. Com o falecimento repentino do sociólogo alemão em janeiro de 2015, torna-se mais que oportuna uma avaliação crítica de suas contribuições e dos desafios que seu legado deixou.

Ainda que Beck tenha se mostrado um cientista prolífico, com uma ampla produção bibliográfica, ele permanece, a rigor, autor de três livros: o seu já referido Risikogesellschaft (2001 [orig. 1986]), Kosmopolitische Blick? (2006 [orig. 2004]) e o seu mais recente Weltrisikogesellschaft (2008 [orig.2007]). O primeiro consiste em um diagnóstico de época acurado; o segundo define o projeto de uma fundação metodológica experimental e transdisciplinar da sociologia; e o terceiro constitui uma reatualização teórica. Ao trazer a questão ambiental para o centro da teoria social, seu trabalho se concentrou na experimentação de aberturas da sociologia para outras disciplinas, notadamente a geografia, antropologia, etnologia, relações internacionais, direito internacional e teoria política (Beck; Sznaider, 2006, p. 382).

O ponto de partida é uma crítica da racionalidade ultraespecializada de uma tecnociência que, aplicados os seus resultados industrialmente, figura ao mesmo tempo como causa e medium de definição de ameaças e catástrofes (Beck, 2001, p. 341-397). Disso resulta uma segunda crítica, que questiona a adequabilidade da sociologia clássica para explicar e compreender uma sociedade que aboliu suas antigas categorias de ordenação (2006, p. 51-68). A partir disso, Beck (2001, p. 20) opta pelo

\footnotetext{
${ }^{1}$ A teoria de Beck foi amplamente mobilizada por pesquisadores de áreas diversas. Entre eles, citamos apenas alguns: Allan et al., 1999; Adam et al., 2000; Guivant, 2000; Ferreira, 2006; lanni, 2012; Tavolaro, 2011; Di Giulio, 2012. Para a consulta dos aspectos gerais da teoria, sugerimos: Vandenberghe, 2001; Mythen, 2004; Bosco, 2013 e 2016 (no prelo).
} 
ensaio como estratégia discursivo-analítica. Compreende-se assim que a conexão entre uma estratégia discursivo-analítica ensaísta, um diagnóstico de época e uma orientação transdisciplinar dá lugar não a uma teoria acabada no sentido convencional, mas a um projeto de conhecimento. Desde 2012, os trabalhos do autor se reuniram em torno do projeto de pesquisa Methodological Cosmopolitanism - In the Laboratory of Climate Change (Beck, 2012).

A marca distintiva da teoria da sociedade mundial de risco reside no esforço de renovação da tradição crítica da teoria social e de uma de suas linhagens específicas, a teoria da modernização. Desde a publicação de seu World risk society em 1999, Beck (2002a, p. 01-28) tem ancorado sua crítica e saída epistemológica na ressignificação do conceito de cosmopolitismo. Para levar a cabo o nosso propósito de avaliação crítica, orientamo-nos por uma breve reconstrução da história da teoria beckiana, situando algumas de suas principais inovações (1). Em seguida, voltamo-nos para duas críticas consolidadas, nomeadamente a crítica à sua fundação histórico-lógica no cosmopolitismo (2) e a crítica epistêmica formulada por teóricos sociais pós-coloniais (3). Percorrido esse caminho, a estratégia metodológica da reconstrução nos permite identificar uma contradição interna entre a fundação da referida teoria no cosmopolitismo metodológico e o diagnóstico dos riscos globais, tendo em vista a tipologia a que este último dá forma (4). E finalmente, formulamos algumas observações críticas, apontamos alguns desafios colocados para a sociologia e sugerimos reorientações de suas perguntas-chave a partir das críticas mencionadas e da intuição teórico-empírica de uma hermenêutica do risco, da reflexividade e da cosmopolitização ainda por fazer (5). 


\section{1 - Modernização-risco-reflexividade, cosmopolitismo metodológico e inovações}

A teoria da sociedade mundial de risco parte de um diagnóstico geral: Perigos são fabricados de forma industrial, exteriorizados economicamente, individualizados no plano jurídico, legitimados no plano das ciências exatas e minimizados no plano político (Beck, 2010, p. 230). Na tentativa de prevenir, mitigar ou remediar riscos e destruições produzidos por sua própria modernização, a sociedade passa a ter de lidar com efeitos não previstos que ela mesma produziu (Beck, 1997). Daí falar-se em modernização reflexiva. Risco e reflexividade constituem, portanto, conceitos centrais: o primeiro permite o acesso à realidade, o segundo explica a lógica de dinamização dessa realidade.

Para o nosso autor, o que diferencia os riscos contemporâneos dos de outras épocas não é tanto o seu potencial de destruição, mas, primeiro, seu aspecto institucionalmente fabricado (pela ciência, pelo mercado, pelo governo etc.) (Beck, 2002a, p. 48-53); segundo, sua invisibilidade, no sentido de que não são perceptíveis pelos sentidos sensoriais humanos (radiação, substância químicas liberadas pela indústria etc.) (Beck, 2001, p. 80-84); e por último, a ausência de fronteira espacial e temporal (idem, p. 65-80). O risco, portanto, não existe por si só, sua objetividade deriva da percepção e da encenação social da qual é objeto (Beck, 2008, p. 4776). Através de sua encenação, o risco define situações sociais de ameaça e, na medida em que caracteriza relações institucionais (Estado, mercado, ciência etc.), são também estabelecidas relações de definição constituídas como relações de dominação, que gravitam em torno de questões de poder, de interesses, benefícios e prejuízos (Beck, 2008, p. 53-60). Temos assim uma condição antropológica geral da sociedade de risco: as destruições e os riscos não podem mais ser atribuídos a causas externas (destino, deuses), é a própria sociedade que os produz e fabrica (manufactured 
uncertainties) (Beck, 2002b, p. 128-135). A sociedade de risco revela, em outras palavras, um "choque antropológico" (Ianni, 2012). Ao dinamizar-se reflexivamente, a sociedade de risco então remete à possibilidade e, em certo sentido, à inevitabilidade da transformação, de se repensar e reinventar o arranjo industrial moderno entre sistema social, sistema econômico e sistema político. A sociedade mundial de risco comporta, portanto, um horizonte político-normativo.

Já em 1986, a sociedade de risco definia teses que se mantiveram inalteradas ao longo dos quase trinta anos seguintes: produção e distribuição dos riscos, individualização reflexiva e modernização reflexiva. Modernização reflexiva designa o movimento geral dessa sociedade, seu aspecto historicamente construído e tendências de desenvolvimento. Por modernização, Beck se refere aos progressos tecnológicos efetuados na racionalização, às transformações do trabalho e da organização, assim como, em sentido amplo, a um processo de implicações muito profundas, que toca e transforma todo o edifício social, e no decorrer do qual são finalmente transformadas as fontes de certeza das quais a vida se alimenta (Beck, 2001, p. 35-36, nota de rodapé).

Na produção e distribuição dos riscos, encontramos uma das teses centrais desse movimento, segundo a qual a produção e distribuição social de riquezas (trabalho, bens, bem-estar social) se veem hoje acompanhadas da produção e distribuição social de riscos (poluição, crises econômicas etc.) (Beck, 2001, p. 35-90; 2008, p. 47-75). Num sentido histórico-sociológico amplo, essa tese sustenta que está a ocorrer uma racionalização (risco; reflexiva) da racionalização (trabalho; simples). Há, nesse sentido, uma radicalização da modernização: a racionalização social impulsionada por uma modernização que produz riquezas e diferencia socialmente pelo trabalho (classe) foi redobrada por uma racionalização social impulsionada por uma modernização que produz riscos 
e diferencia socialmente pela insegurança (comunidades ou grupos de risco) (Beck, 2011). A essa tese são associados os riscos globais ambiental e financeiro.

De seu lado, a individualização reflexiva sustenta que, em virtude do melhoramento das condições gerais de existência e do desenvolvimento das instituições modernas, assistimos a uma desincorporação das identidades sociais. Como efeito derivado da construção do Estado de bem-estar social, dos progressos da ciência e do desenvolvimento das forças produtivas, inicia-se um processo de diversificação das condições de vida, que substitui aquelas da sociedade industrial (classe, família nuclear etc.) por outras, mais "flexíveis", individualizadas, logo, mais "arriscadas" (Beck; Beck-Gernsheim, 2002). Sendo produto da escolha individualizada, a biografia passa a contar com mais incertezas: por um lado, abrem-se novas possibilidades de realização pessoal, mas por outro, individualiza-se a desigualdade social (Beck, 2001, p. 158-335). À individualização reflexiva corresponde o risco global biográfico.

Nessa dinamização reflexiva, questões de calculabilidade e previsibilidade do risco ganham importância para a ação e a regulação institucional (Beck, 1997, p.45-47; 2002a, p. 75-103). Sendo assim, modernização reflexiva também - e essencialmente - significa "reforma da racionalidade", a qual faz justiça à ambivalência histórica a priori em uma modernidade que está abolindo suas próprias categorias de ordenação (Beck, 1997, p. 47). A crítica da racionalidade está aqui dirigida à ultraespecialização do conhecimento científico. É a ultraespecialização, argumenta o autor, que está na origem da incontrolabilidade dos efeitos colaterais, pois isola em laboratório resultados que, uma vez aplicados industrialmente, deixam de permanecer isolados, tornando-se mais complexos e imprevisíveis. O eixo teórico modernização-risco-reflexividade fica assim definido: na esteira da modernização continuada e de seus sucessos, são produzidos riscos e 
destruições de alcance mundial que, percebidos socialmente como ameaça, estimulam formas reflexivas de socialização e fazem emergir uma nova sociedade, a sociedade mundial de risco.

A partir da publicação de seu World Risk Society em 1999 (2002a), o teórico social reorienta a interpretação da acepção global dos riscos a partir de uma resignificação do conceito de cosmopolitismo. Uma vez que os riscos não possuem fronteiras espaciais nem temporais, argumenta Beck no transcorrer dos anos seguintes, sua encenação social promove uma cosmopolitização reflexiva forçada da vida social (Beck, 2006, p. 69$98,169-188)$. A vida social se cosmopolitiza na medida em que um futuro antecipado como catástrofe se introduz no presente como força de integração política e social transnacional (Beck, 2008, p. 34-37). É um futuro arriscado industrialmente induzido, cientificamente antecipado, politicamente gerido, socialmente percebido e mundialmente compartilhado na ação presente que força uma cosmopolitização reflexiva da sociedade e da história. A consequência disso é uma diferenciação qualitativa da sociedade contemporânea, que permitiria distinguir entre uma primeira e uma segunda modernidade (Beck, 2000).

Diante disso, Beck sustenta que, se o que caracteriza a sociedade (de risco) contemporânea é, no plano societário, a cosmopolitização reflexiva e, no plano da racionalidade científica, o reconhecimento de limites compreensivos e explicativos do quadro de referência disciplinar e clássico, torna-se necessária uma refundação da sociologia no sentido cosmopolita. O cosmopolitismo metodológico parte da diferenciação teórica entre perspectiva do ator (versão histórica) e perspectiva do observador em ciências sociais (versão lógica) e da vinculação metodológica de uma dimensão espacial (território) com uma dimensão temporal (história).

Para Beck, as teorias da primeira modernidade são marcadas por um nacionalismo metodológico (perspectiva do observador), o qual, enquan- 
to reflexo da ótica nacional (perspectiva do ator), assimila o conceito de sociedade ao de Estado-nação (Beck, 2006, p. 52-68). A consequência de tal assimilação é o estabelecimento de uma lógica de distinção exclusiva como orientação para a formulação de conceitos e categorias - alemão ou turco, ciências do espírito ou ciências da natureza, sociedade ou natureza, e assim por diante. Uma vez que a sociedade se cosmopolitizou, seria então necessário um equivalente na perspectiva do observador: o cosmopolitismo metodológico, fundado em uma lógica de distinção inclusiva - alemão e turco, ciências sociais e ciências da natureza, sociedade e natureza. No plano teórico, almeja-se aqui uma mudança de paradigma, do exclusivo para o inclusivo, do simples para o reflexivo, do nacional para o cosmopolita. Isto é, Beck advoga por uma ruptura epistemológica.

No plano metodológico, a dimensão espacial substitui o primado de relações nacionais-nacionais por relações translocais, locais-globais, transnacionais, nacionais-globais e globais-globais (Beck, 2006, p. 151). A dimensão espacial da cosmopolitização deve ser pensada em relação à dimensão temporal. Com a dimensão temporal, questões empírico-analíticas e normativas se abrem para a cosmopolitização da sociedade e da política, da história e da memória: [...] qual 'realidade' assume a globalização dos riscos e das crises num contexto marcado pela diversidade das vivências históricas, e de qual elaboração política pode ela ser objeto? (idem, p. 153-154). A orientação político-normativa do diagnóstico fica como segue: enquanto no nacionalismo metodológico, argumenta o autor, têm centralidade para a ação e a consciência as implicações futuras de um passado compartilhado no nível nacional, no cosmopolitismo metodológico trata-se de implicações presentes de um futuro compartilhado no nível global que não se funda num passado comum (Beck, 2008, p. 31-32). Tidas em conjunto, nesse sentido, as dimensões espacial e tempo- 


\section{ral definem como orientação metodológica geral uma trans-historicidade} (do risco) vinculada à territorialidade.

A diferenciação teórica (perspectiva do ator/do observador) e a vinculação metodológica (dimensão espacial e temporal) estão inscritas na distinção histórica de fases de uma primeira e de uma segunda modernidade, como sintetiza o seguinte quadro:

Quadro 1. Representação da história da sociedade moderna derivada da ancoragem da teoria da sociedade mundial de risco no cosmopolitismo metodológico

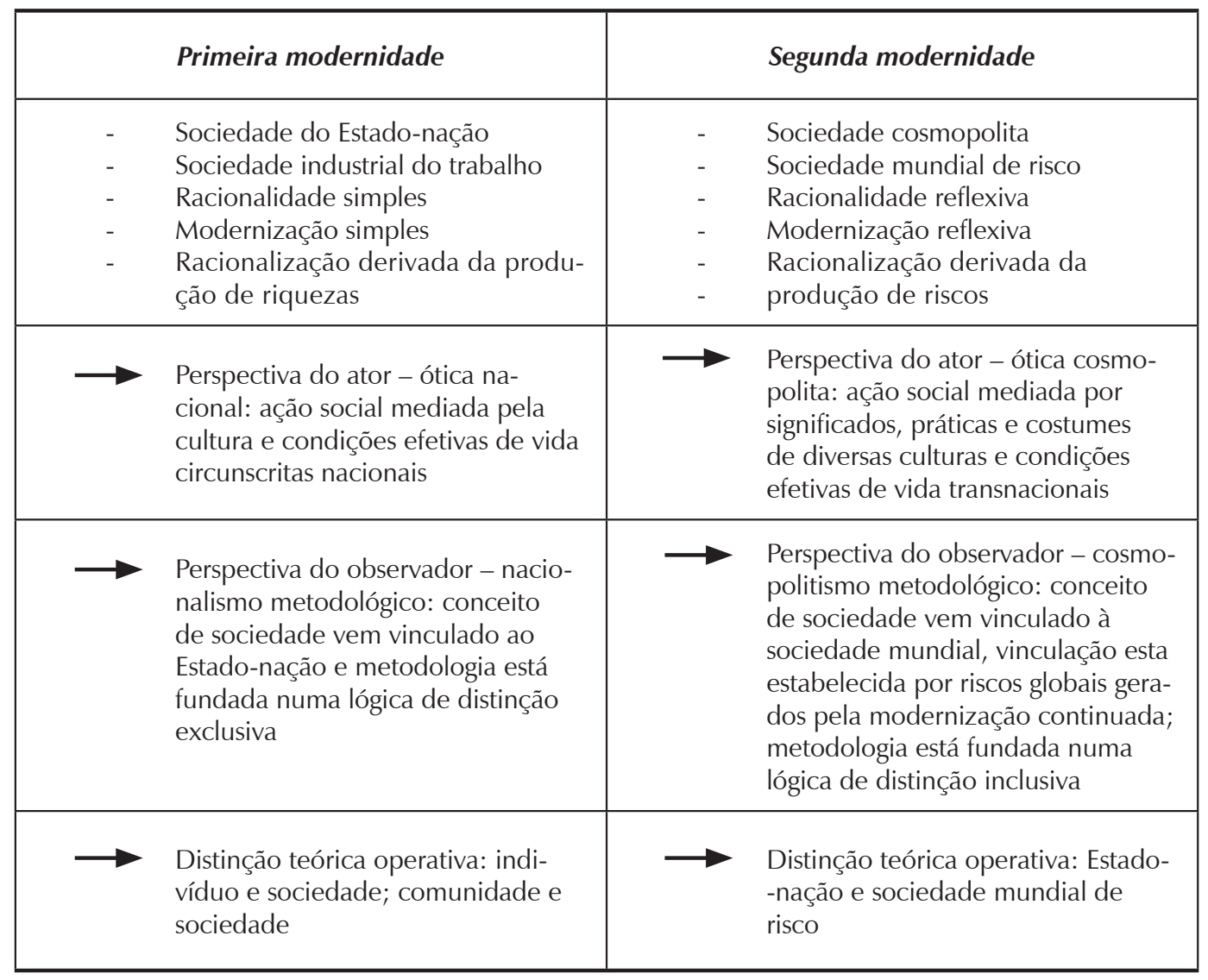


De um modo geral, a intuição teórico-empírica de Beck é promissora. Quando afirma que a dinâmica dos riscos ambientais só pode ser compreendida a partir de um cosmopolitismo metodológico (2008, p. 219254), o autor logra conectar um fenômeno concreto como as mudanças ambientais com uma categoria de circulação mundial (risco ambiental) - marcada por significações culturais diversas - e ainda definir um quadro de referência teórico-metodológico. Em um sentido amplo, o risco - agora não mais apenas o ambiental, mas também o financeiro, o biográfico e o terrorista (2008, p. 32-34) - promove o surgimento de comunidades cosmopolitas de risco, as quais materializam uma interdependência crescente no interior da sociedade mundial (2011).

A teoria da sociedade mundial de risco traz, portanto, algumas inovações. No âmbito dos estudos sobre governança do risco, uma vez que logra caracterizar determinados riscos como um fenômeno de circulação global, por um lado ela permite a vinculação objetiva entre o universo gerencial do Estado nacional e a globalização, num contexto em que uma política de governo tenha sua legitimidade e eficácia mediadas por esferas de regulação pós-nacionais (Beck, 2002b, p. 48-65, 214-221); por outro, permite a elaboração de novas formas de participação direta nos processos de tomada de decisão no interior do sistema político, de modo a redesenhar as bases de legitimação da política estatal (Beck, 2010, p. 234-238).

Segundo, a questão ambiental deixa de ser tratada como um problema ambiental e passa a figurar como problema interno da sociedade (Beck, 2001, p. 146-153; 2002a, p. 41-48). Rompe-se, assim, com a separação moderna entre sociedade e natureza, redefinindo-a com base num princípio de reciprocidade e abrindo, consequentemente, novas perspectivas para a teoria social, no sentido de estratégias que permitam lidar com problemas que transcendem as divisões disciplinares convencionais (Beck, 2001, p. 347-356, 395-398, 485-493; 2002a, p. 113-141). 
E terceiro, sua inovação está dirigida para o conceito de sociedade. Com base no eixo teórico modernização-risco-reflexividade, desprende-se uma concepção de sociedade mundial que, segundo Beck, pode operar como referência metodológica para uma renovação da sociologia: a estreita vinculação dos processos de definição social dos riscos e da encenação social dos mesmos com as novas formas de classificar, interpretar e organizar nosso cotidiano (Beck, 2008, p. 37), implica afirmar que crer na antecipação da catástrofe desarraiga as hierarquias sociais da sociedade industrial, reorganiza a configuração sociológica do conflito e internaliza sociologicamente a natureza por meio de uma cientifização reflexiva.

O conceito de sociedade contido na expressão "sociedade de risco" determina quatro dimensões constitutivas: a interação - leia-se, a elaboração de um discurso sobre o risco -, a decisão, a controlabilidade dos efeitos derivados de decisões e a localidade como contexto de manifestação dos riscos globais (Beck, 2008). Nessa sociedade, questões envolvendo legitimidade, aspirações existenciais, inovação, desafios de produção e distribuição, são mediadas não mais apenas pela capacidade das instituições nacionais de criar certezas, mas também e principalmente por sua habilidade para estabelecer vínculos cooperativos com arranjos institucionais diferentes, transnacionais, transdisciplinares e sensíveis aos problemas decorrentes da padronização das biografias. Por sua habilidade, em suma, para lidar, de modo cosmopolita, com as incertezas de um futuro aberto. Compreende-se assim que a força da teoria da sociedade mundial de risco reside na combinação heurística entre uma descrição ampla da modernização e uma análise normativa orientada para os potenciais de emancipação de uma modernização da modernização (Latour, 2003). 


\section{2 - A crítica da crítica do nacionalismo metodológico}

É difícil discordar da interpretação teórica de Beck quando aponta, na sociologia clássica, para uma correspondência quase-tácita entre o conceito de sociedade e o de Estado-nação. Entretanto, como salientam Robert Fine e Daniel Chernilo, o problema da crítica do nacionalismo metodológico formulada por Beck está em seu "presentismo" e na insuficiente diferenciação conceitual entre a versão histórica (perspectiva do ator) e a versão lógica (perspectiva do observador) do nacionalismo. Isto é, a crítica de Fine e Chernilo circunscreve a diferenciação teórica entre perspectiva do ator e perspectiva do observador do cosmopolitismo metodológico de Beck e se volta para a representação da trajetória da sociedade moderna daí decorrente. Essa insuficiente diferenciação resulta em um "esquematismo histórico-teórico" que impede de atender à designação cosmopolita pretendida.

Robert Fine (2007, p. 09 sq.) delineia dois problemas metodológicos decorrentes desse esquematismo. Primeiro, o cosmopolitismo metodológico diferencia e vincula de modo sucessivo uma primeira modernidade, simples, industrial e nacional, a uma segunda modernidade, reflexiva, pós-industrial e cosmopolita. Essa concepção sucessiva do processo histórico comporta duas insuficiências analíticas graves. Por um lado, argumenta Fine, o passado nacional da modernidade é tido como um período marcado apenas por um estado de guerra de todos contra todos, deixando de lado revoluções com aspirações mundiais, impérios multinacionais, a Liga das Nações, o nacionalismo de aspiração mundial, entre outros. Há, nesse sentido, um "presentismo" autorreferenciado, que contesta a validade de teorias, categorias e conceitos estabelecidos ao simplesmente anunciar o surgimento de uma nova era cosmopolita, distante da era nacional no plano societário e da ação política. 
Por outro lado, estabelecer um vínculo sucessivo entre uma primeira e uma segunda modernidade não atende à mudança de perspectiva preconizada pelo cosmopolitismo metodológico, que advoga pela necessidade de ter a sociedade mundial como referência metodológica. Definir uma primeira modernidade como nacional e uma segunda como cosmopolita significa tomar a história da Europa ocidental como história mundial. Essa segunda insuficiência remete ao problema do autorreferenciamento epistêmico e se alinha, como veremos, à crítica pós-colonial.

Segundo, ao afirmar que o cosmopolitismo metodológico deve estar voltado para implicações futuras de ações presentes, deixando de lado a análise das implicações presentes de um nacionalismo tido como relíquia da história e, com isso, declarando a redundância de antigos conceitos e categorias, o cosmopolitismo metodológico tende a abrir mão de categorias e conceitos que possibilitam compreender como justamente acontecimentos, problemas e redes comunicativas (como o risco, os direitos humanos, as crises econômicas etc.) assumem expressões heterogêneas na esfera local, combinando-se com histórias locais. O aspecto polissêmico de problemas compartilhados mundialmente possui estreita vinculação com redes de influências de manifestação local.

Em proximidade com Fine, Daniel Chernilo (2006) argumenta que o "presentismo" e o resultante "esquematismo histórico-teórico" da crítica do nacionalismo metodológico formulada por Beck impedem de compreender que o nacionalismo metodológico era tão metodologicamente infundado na primeira modernidade como é na segunda. Os conceitos e categorias de um passado nacional, simples e industrial da modernidade não apenas perdem validade porque o mundo passou por transformações radicais, tornando-se cosmopolita, reflexivo e pós-industrial, mas substancialmente porque tais transformações iluminaram novos aspectos das formas de socialização. O que se torna questionável, portanto, é o posicionamento de ruptura no plano lógico. 
Para Chernilo, o nacionalismo metodológico e a autocompreensão que ele gera eram empiricamente falsos também para compreender a autoimagem nacional das sociedades da primeira modernidade. A correspondência entre Estado-nação e sociedade leva, no plano lógico, a uma concepção empiricamente falsa de transformação social, a qual seria endógena e autossuficiente. Chernilo conclui que o nacionalismo metodológico surgiria então quando a perspectiva intelectual da sociologia está baseada na equação entre sociedade e Estado-nação, por um lado, e na explicação substantiva da transformação social contida nessa concepção internalista e autossuficiente de Estado-nação, por outro (Chernilo, 2006, p. 08).

A crítica de Chernilo delineia, por fim, duas versões da crítica do nacionalismo metodológico: uma primeira, lógica, versada sobre implicações metodológicas no âmbito da formulação de conceitos e categorias, outra histórica, que se dedica a compreender como uma forma contingente de organização política da modernidade acabou por assumir o estatuto de organização natural da sociedade moderna e encarnar o projeto moderno. Essa distinção é fundamental para delinear com clareza os significados e implicações que o nacionalismo metodológico tem para a sociologia. A ausência dessa distinção fundamental entre a versão lógica e a versão histórica é o que leva Beck, sustenta o autor, a cometer o equívoco de deixar entender que o nacionalismo metodológico era adequado para o seu tempo, tendo por consequência uma oposição lógica entre nacionalismo e cosmopolitismo ancorada em uma concepção esquemática do tempo histórico. A consequência teórica disso é a de que Beck acaba por definir, talvez inadvertidamente, equivalentes lógicos do nacionalismo metodológico para pensar um tempo presente que ele mesmo considera como radicalmente distinto. De um modo paradoxal, Beck cria uma versão renovada do dualismo mais famoso da teoria social: ele tem a própria versão da dicotomia entre Gemeinschaft - agora o Estado-nação e Gesellschaft - a sociedade mundial de risco (Chernilo, 2006: 12). 
Para evitar o "esquematismo histórico-teórico", Chernilo sustenta que é necessário operar as duas versões do nacionalismo metodológico, a lógica e a histórica, conjuntamente. Isso evitaria o equívoco de vincular teoricamente um conceito dotado de uma pretensão universal de validade (sociedade) a um aspecto histórico contingente (Estado-nação). É esse equívoco que Beck reproduz ao deixar entender que o nacionalismo metodológico foi adequado para o seu tempo e que, à luz de transformações históricas (perspectiva do ator), haveria de se colocar em marcha uma ruptura epistemológica (perspectiva do observador). Ao não diferenciar essas duas versões da crítica do nacionalismo metodológico, o conceito de sociedade contido em "sociedade mundial de risco" tende igualmente a estar mediado por um aspecto historicamente contingente do tempo presente: o risco e o tipo de cosmopolitização reflexiva que ele engendra.

Nesse sentido, tanto Chernilo quanto Fine argumentam que nacionalismo e cosmopolitismo devem ser reconstruídos não como opostos no plano lógico e no plano histórico, mas como co-originários e em coevolução. Os autores concordam com as teses principais da crítica do nacionalismo metodológico e compartilham do potencial lógico, histórico e político do cosmopolitismo. Mas opõem-se a uma concepção histórica e lógica esquemática, como faz Beck.

Entretanto, apesar de bem-sucedidos no âmbito da diferenciação conceitual no interior da crítica do nacionalismo metodológico, o caminho aberto para uma teoria social cosmopolita ainda carece, na interpretação de Fine e Chernilo, de um posicionamento teórico mais bem definido no que tange ao lado imperialista e colonial do Estado-nação. Os equívocos de uma concepção autossuficiente de sociedade e endógena de transformação social, advinda da correspondência teórica entre sociedade e Estado-nação, têm suas consequências teóricas mais evidentes quando pensados à luz de uma teoria da modernização efetivamente mundial, como aponta a crítica pós-colonial. 


\section{3 - A crítica pós-colonial da modernização reflexiva e do cosmopolitismo}

A crítica pós-colonial também circunscreve a diferenciação teórica entre perspectiva do ator e perspectiva do observador e se volta para a representação da trajetória da sociedade moderna daí decorrente. Mas diferentemente de Fine e Chernilo, enfatiza-se aqui o caráter epistêmico dessa representação. O problema geral identificado pelos estudos pós-coloniais circunscreve a inscrição da teoria da sociedade mundial de risco no campo da teoria da modernização. Mais precisamente, Sérgio Costa (2006) e Gurminder Bhambra (2011) se dirigem à conversão em axioma da dedução teórica segundo a qual a modernização autossuficiente e endógena da Europa/Ocidente precede linearmente e determina teleologicamente a modernização do resto do mundo. A consequência teórica disso é a correspondência da autocompreensão de determinada sociedade política, econômica e técnico-cientificamente dominante com o devir social do conjunto da sociedade mundial. A consequência histórica, de seu lado, é a exclusão hermeneuticamente arbitrária daquilo que não é reconhecido pela autocompreensão de mundo europeia/ocidental. Ao localizar reflexividade e cosmopolitismo no esquematismo histórico-teórico de uma modernização ocidental precedente e teleologicamente determinante das demais, Costa e Bhambra identificam na modernização reflexiva e na cosmopolitização reflexiva um autorreferenciamento epistêmico.

Para Costa, o autorreferenciamento epistêmico da teoria da sociedade mundial de risco se expressa, primeiramente, como reducionismo. A cosmopolitização reflexiva desencadeada pelo risco, argumenta o autor, não consiste senão em uma categoria única que está longe de identificar a "multiplicidade radical" das transformações recentes. No plano analítico, isso quer dizer renunciar à tentação reducionista de fundir várias dinâmicas numa única categoria (Costa, 2006, p. 122). 
Em segundo lugar, conceitos como risco e cosmopolitização reflexiva padecem de um déficit histórico e historiográfico evidente, além de desconsiderarem as tensões entre os níveis geográficos de análise (Costa, 2006, p. 122-23). Esse déficit histórico, historiográfico e geográfico constitui o pano de fundo do autorreferenciamento epistêmico do modelo de fases da modernidade da sociedade mundial de risco: Esse modelo encontra, possivelmente, aplicação em algumas sociedades europeias; contudo, em regiões que se integraram ao mundo moderno na condição de colônia e sociedade escravagista, o espírito crítico chegou muito antes das certezas (modernas). De algum modo, essas sociedades já eram "reflexivas" muito antes de se industrializarem (2006, p. 220). De certa maneira, portanto, Costa acrescenta ao "esquematismo histórico-teórico" identificado por Chernilo e Fine uma dimensão propriamente histórica e geográfica que insere o Estado-nação no contexto da sociedade mundial.

Terceiro, tais deficiências levam Beck a substituir uma imagem de mundo composta por sociedades do Estado nacional tidas como "mônadas sociológicas" por uma baseada na antinomia West/Rest. Beck substitui o autorreferenciamento do nacionalismo pelo autorreferenciamento de um cosmopolitismo ocidental. É esse autorreferenciamento que faz com que o autor reduza o diagnóstico da modernização mundial ao risco e à cosmopolitização reflexiva. A implicação teórico-normativa disso é a seguinte: uma vez que a racionalidade reflexiva observada em sociedades europeias configura um potencial de emancipação transferido para o conjunto da sociedade mundial, Beck desconsidera a materialidade local do risco, as interpretações culturalmente localizadas dos mesmos e o diagnóstico imanente de potenciais de emancipação. Assim, no lugar da adequada consideração da diversidade dos variados padrões de transformação nas diferentes regiões do mundo nominalmente almejada pelo autor, sua perspectiva de análise acaba descrevendo a globalização como processo 
evolucionista e monocêntrico de expansão de uma certa "constante" social, a reflexividade (Costa, 2006, p. 77).

A insuficiência da teoria de Beck e de seu cosmopolitismo reside, nesse sentido, no lugar que este último passa a ocupar no modelo de fases da modernidade: se a primeira modernidade se caracteriza pelo surgimento do Estado-nação e do nacionalismo e a segunda, a reflexiva, se diferencia da primeira por sua dinamização cosmopolita e o autoconfrontamento com a racionalidade institucional da primeira, então o cosmopolitismo fica restrito à história europeia. Esse esquematismo histórico-teórico eurocêntrico dá lugar, consequentemente, a binarismos variados: simples vs. reflexivo, nacionalismo vs. cosmopolitismo, West vs. Rest.

De seu lado, as críticas de Gurminder Bhambra (2011) partem de uma dedução inicial: ao reproduzir a antinomia entre Ocidente e o Resto, a crítica do nacionalismo metodológico formulada por Beck e seu desdobramento em cosmopolitismo metodológico reduzem a sociedade mundial à autocompreensão europeia. Como nos clássicos da sociologia, argumenta a autora, a crítica do nacionalismo metodológico do sociólogo alemão permanece cega às estruturas imperiais que conferiram proporção mundial à modernização europeia no período da primeira modernidade. E a mesma cegueira se mantém no cosmopolitismo metodológico em relação à reatualização daqueles mecanismos de dominação imperiais no contexto pós-colonial, antes crivados na ocupação militar, hoje mediados pela economia política global e pela concentração da enunciação.

Quando argumento que os conceitos sociológicos são inapropriadamente elaborados - especialmente, que eles são "metodologicamente eurocêntricos", ao invés de metodologicamente nacionalistas -, isso não é algo que está se tornando problemático apenas agora [...] No mínimo [...] a "primeira fase da modernidade" está caracterizada tanto por impérios quanto por Estados-nação, então os conceitos dessa fase seriam tão inadequados naquela época quanto seriam agora (Bhambra, 2011, p. 317). 
Bhambra argumenta que quando Beck vai do nacionalismo ao cosmopolitismo, mantém-se o autorreferencimento epistêmico das teorias clássicas, do nacional para o ocidental. Se levarmos às últimas consequências o argumento de Bhambra, temos o seguinte quadro: da primeira para a segunda fase da modernidade, trata-se da passagem de um "eurocentrismo metodológico", que toma a forma de organização político-social de parte da Europa ocidental (Estado-nação) como modelo mundial de análise, para um "ocidentalismo metodológico", que toma a organização político-social (democracia liberal e unificação europeia) e padrões de integração social das sociedades ocidentais como modelo mundial de análise. Circunscrever o cosmopolitismo às tradições de pensamento ocidentais acarreta três problemas teórico-metodológicos:

Primeiro, há a recusa de reconhecer que houve práticas cosmopolitas e o desenvolvimento de ideias cosmopolitas em outras partes do mundo, fora do contato europeu, em relação ao contato europeu e não subordinadas ao contato europeu [...] Segundo, não há engajamento em relação à tensão problemática trazida à tona quando nós (se existe um nós) abordamos a dominação europeia contemporânea sobre boa parte do mundo enquanto a negação real da ideia e dos ideais que o cosmopolitismo, todavia, reivindica [...] E ainda, enquanto abre-se espaço para considerar diferentemente as histórias-padrão do cosmopolitismo, essas histórias também reproduzem justamente aquilo a que eles lautores dos discursos dominantes sobre o cosmopolitismo contemporâneo] se opõem e, em muitos casos, o que é reproduzido [...] é uma genealogia europeia. Não é que tais formas de universalismo são peculiares à Europa, mas antes que a Europa parece ter sérias dificuldades com o universalismo que abraça (Bhambra, 2011, p. 315).

A desconstrução da episteme moderna ocidental e de sua antinomia atual West/Rest define o ponto de entrada pós-colonial no debate sobre o cosmopolitismo, eo ipso, sobre o nacionalismo. Dessa maneira, estabe- 
lece-se uma relação crítica com tradições de pensamento ocidentais. Na sociologia, privilegia-se a teoria da modernização, no sentido preciso de que a pretensão universal de validade ali avançada define o que é e o que não é moderno sem se dar conta da encarnação etnocêntrica de suas formulações. Transposto isso para o discurso cosmopolita da modernização reflexiva de Beck, trata-se então de uma definição "ocidentalocêntrica" do que é ou não é cosmopolita (Bhambra, 2011, p. 314).

Se não considerarmos a diversidade que o cosmopolitismo ilumina enquanto encarnação antropológica generativa intercultural, o potencial analítico do conceito fica restrito a uma compreensão "paroquial" do que significa enquanto prática social. Enquanto estudiosos argumentam a favor do universalismo do que é pressuposto como categorias europeias, eles então raramente reconhecem os processos através dos quais tal universalização é ativada, a saber, majoritariamente processos de colonização e imperialismo (Bhambra, 2011, p. 314). Vincular de modo exclusivo e precedente o cosmopolitismo à modernização ocidental, à democracia liberal ocidental e às tradições de pensamento ocidentais, implica em operar um fechamento hermenêutico arbitrário da encarnação antropológica generativa intercultural do conceito. Diversidade cultural, práticas sociais cosmopolitas e a "reflexivização" que as caracterizam, não são exclusivas da vida social ocidental. Muito pelo contrário: a diversidade cultural é característica histórico-sociológica constitutiva das sociedades pós-coloniais, o que sugere a indagação empiricamente razoável de que práticas sociais cosmopolitas podem ter existido no período da "primeira" modernidade e existam em sociedades não ocidentais² ${ }^{2}$

\footnotetext{
${ }^{2}$ Ver a esse respeito, por exemplo, os estudos aplicados realizados por Glynn e Cupples (2010) e Gidwani e Sivaramakrishnan (2003), que identificam práticas sociais cosmopolitas, respectivamente, entre indígenas na Costa do Mosquito, Nicarágua, e no espaço social rural da Índia.
} 
As críticas pós-coloniais de Costa e Bhambra, portanto, não apenas reconhecem as limitações das teorias clássicas da modernização que a crítica do nacionalismo metodológico identifica, mas conferem a esta última uma perspectiva mundial, ao analisar o Estado-nação além da autocompreensão nacionalista europeia: a saber, também consideram analiticamente o imperialismo e o colonialismo. Em sentido amplo, trata-se aqui, como definem Sebastian Conrad e Shalini Randeria (2002, p. 25-26), de abrir a análise sociológica, antropológica e histórica para a coprodução do mundo moderno, para a perspectiva de "modernidades entrelaçadas" (entangled modernities). Em vista disso, o que falta ao cosmopolitismo da teoria da sociedade mundial de risco é justamente um procedimento metodológico reflexivo mundial; é fazer valer cognitiva, teórica e normativamente a reflexividade que reivindica.

\section{4 - A contradição interna: cosmopolitismo metodológico e tipologia dos riscos globais}

As críticas de Chernilo e Fine, por um lado, e de Costa e Bhambra, por outro, apontam para um problema comum, qual seja: o risco que representa tomar-se uma história social determinada como referência metodológica para derivar uma condição de vida e potenciais de emancipação mundiais. No plano normativo, fazer valer worldwide o diagnóstico de potenciais de emancipação histórica e geoculturalmente localizados tende a configurar uma concepção metafísica de "bem comum", que ao estar dissociada das condições efetivas de vida próprias a outro contexto histórico de ação, pode induzir a formas de violência e dominação. Neste momento, gostaríamos de introduzir uma crítica à tradução falha da imbricação metodológica das dimensões espacial e temporal do cosmopolitismo metodológico no diagnóstico dos riscos globais levado a cabo por 
Beck. No plano conceitual, isso revela equívocos particularmente graves, como fica explícito na tipologia dos riscos globais, a qual diferencia os riscos ambiental, financeiro, terrorista e biográfico a partir do binômio casualidade/intenção (Beck, 2008, p. 32-34).

O tipo ambiental (Beck, 2001, p. 43-48 e 65-80; 2008, p. 62-66) e o tipo financeiro (Beck, 2008, p. 270-273) possuem, apesar de suas particularidades intrínsecas, um eixo comum: ambos se inscrevem na ação como casualidade, como efeito imprevisto de decisões tomadas no processo de modernização. Ambos possuem, ainda, a dialética entre bens e prejuízos como ambivalência constitutiva do ponto de vista político-institucional e técnico-científico. Riscos financeiros envolvendo construções de novas centrais nucleares, por um lado, e riscos ambientais relativos à destruição ecológica, por outro, se confundem numa espécie de zona subversiva de incalculabilidade, fazendo com que em muitas decisões que comportam grandes riscos, não se trate de escolher entre alternativas seguras e alternativas arriscadas, mas entre várias alternativas arriscadas; alternativas cujos riscos se mostram frequentemente incomensuráveis, já que afetam âmbitos qualitativamente diferentes (Beck, 2008, p. 18). Enquanto catástrofe antecipada, os riscos ambientais e financeiros escapam à racionalidade institucionaliza como imprevisibilidade, porque surgem da incerteza derivada do déficit racional da imaginação e medição científicas, da incalculabilidade.

O autorreferenciamento epistêmico que essa definição de riscos ambiental e financeiro carrega reside no fato de que a conscientização em relação aos riscos e o problema da legitimação dos efeitos destrutivos de riscos que se convertem em catástrofe pressupõem uma sociedade organizada politicamente como democracia, posto que nela não há controle do conteúdo das informações veiculadas pelos meios de comunicação; nela há garantias jurídicas para o exercício de liberdades fundamentais; e nela, ain- 
da, o poder político tem sua fonte de legitimidade na soberania popular. $\mathrm{O}$ autorreferenciamento epistêmico consiste em que, como decisões tomadas no processo de modernização, os riscos ambiental e financeiro assumem uma dinamização institucional ambivalente porque não podem prescindir, na democracia, da legitimação pública das decisões político-institucionais e da aplicação industrial de resultados técnico-científicos ${ }^{3}$.

Já o risco terrorista pressupõe uma intencionalidade da ação (Beck, 2008, p. 213-218 e 273-274). Consequentemente, a catástrofe nele antecipada escapa à racionalidade fundamental pela qual é feito o cálculo do risco - previsibilidade frente a acidentes possíveis. A ação institucional reguladora passa então a incentivar, de forma moralmente justificada, a imaginação com intenção preventiva. Contudo, ao incentivar a imaginação de modo a ir além de acidentes meramente fortuitos, o Estado de direito tende a suprimir os fundamentos da liberdade e da democracia (Beck, 2008, p. 34).

O autorreferenciamento epistêmico do risco terrorista se manifesta em dois aspectos precisos. Por um lado, pressupõe-se a perspectiva da vítima do ato terrorista. $\mathrm{O}$ fenômeno maior que representa o terrorismo fica reduzido à autocompreensão geoculturalmente localizada da vítima e à ação deliberada de um "Outro fixo no tempo e no espaço", deixando de ser compreendido como contra-ação à reatualização histórica do imperialismo - do imperialismo colonial da Europa ocidental para o imperialismo econômico do Ocidente. Essa contra-ação está inscrita numa condição de vida pós-colonial. Por outro lado, pressupõe-se a forma de organização política do Estado democrático de direito e problemas específicos de legitimação da ação institucional preventiva no plano dos fundamentos da liberdade e da democracia.

\footnotetext{
${ }^{3}$ Para conferir a vínculo interno entre riscos ambientais, financeiros e democracia, sugiro: Beck, 2001, p. 35-159; 2008, p. 18, 34 e 45)
} 
Por último, o risco biográfico se refere à insegurança nas biografias e funda-se tanto na casualidade como na intencionalidade. Casualidade, porque eventos fortuitos (acidentes, doenças) podem impedir ou dificultar a realização de objetivos pré-determinados. Intencionalidade, porque institucionalmente exige-se do indivíduo escolhas entre caminhos a seguir no transcorrer da biografia individual (carreira, formação, filhos) e que o mesmo se previna contra possíveis acontecimentos e fatalidades (seguro de saúde, de vida, aposentadoria privada) (Beck, 2001, p. 295-336; Beck \& Beck-Gernsheim, 2002, p. 89-90; 140-144). O risco biográfico diz, então, respeito à condição de experiência do indivíduo numa sociedade em que o percurso biográfico deixa de ser conformado exclusivamente pela origem social, pela família nuclear, pela religião, situando-se também na relação entre experiência individualizada e padronização institucional das biografias. A consequência disso consiste em que as antigas solidariedades (de classe) são substituídas por solidariedades seletivas (Beck, 2001, p. 165-216; 2002b, p. 67-112; Beck \& Beck-Gernsheim, 2002, p. 01-21 e $33-41 ; 2008$, p. 41-58).

O autorreferenciamento epistêmico se revela aqui em dois aspectos geoculturais. Primeiro, pressupõe-se democracia, mercado capitalista, modelo familiar cristão-burguês, sistema de seguridade social do Estado de bem-estar. Segundo, pressupõe-se também uma trajetória da sociedade moderna determinada, que vai de uma modernidade simples para uma reflexiva e acompanhada por processos de secularização e racionalização crescentes que, ao cabo, estimularam formas individualizadas de socialização.

Compreende-se assim que a tipologia dos riscos globais está encarnada na trajetória histórica específica e na autocompreensão "presentista" de uma sociedade moderna europeia/ocidental. À luz dessa tipologia, isso significa, a rigor, que a autocompreensão da sociedade de risco está longe 
de ser mundial, como pretende Beck, mas corresponde, no limite, à autocompreensão da sociedade de risco europeia/ocidental. Em vista disso, ganha forma uma contradição interna no projeto de Beck, precisamente na tradução das dimensões espacial e temporal do cosmopolitismo metodológico (versão lógica) em um diagnóstico de época (versão histórica), com sua tipologia eurocêntrica dos riscos globais: o autor não logrou traduzir as dimensões espacial e temporal do cosmopolitismo em seu uso heurísitico do risco.

No plano espacial, a substituição de relações nacionais-nacionais por relações translocais, locais-globais, transnacionais, nacionais-globais e globais-globais (Beck, 2006, p. 151) consistiu, finalmente, em substituir relações nacionais-nacionais (nacionalismo metodológico) por uma relação de viés hermenêutico unilateral, a relação West/Rest. Essa tradução falha da dimensão espacial do cosmopolitismo metodológico em um diagnóstico de época se desdobra, por sua vez, no horizonte normativo da sociedade de risco: ao partir dos dilemas que a globalização traz para a democracia e o Estado de direito, Beck tende a restringir o horizonte normativo da sociedade mundial aos dilemas circunscritos por um locus histórico europeu. Em um artigo intitulado Understanding the real Europe (Compreendendo a verdadeira Europa), a unilateralidade hermenêutica fica particularmente clara: Mais do que em qualquer outra parte do mundo, a Europa mostra que esse passo é possível. A Europa ensina ao mundo moderno que a evolução política centrada no Estado nacional e nos sistemas de Estado chegou, sem sombra de dúvida, ao fim [...] O slogan para o futuro poderia ser: o movimento América-Europa está de volta! (Beck, 2003, p. 38).

Em suma, como bem resume Bhambra, a versão de cosmopolitismo de Beck é uma expressão de eurocentrismo cultural mascarado como inclusividade global potencial, que é dependente do fato de Eles serem incluídos em Nossos modelos (2011, p. 325). Essa tradução falha da di- 
mensão espacial no diagnóstico de época conduz, ainda, a uma falha na tradução da dimensão temporal, já que ambas estão internamente vinculadas: a unilateralidade hermenêutica da relação West/Rest e a restrição que isso opera no horizonte normativo da sociedade mundial impedem justamente de abrir o olhar para questões empírico-analíticas, mas também normativas, que decorrem da cosmopolitização da sociedade e da política, da história e da memória - como quer Beck (2006, p. 154-55).

Compreende-se aqui que a falha em traduzir as dimensões espacial e temporal em um diagnóstico de época cosmopolita tende a desenhar um horizonte normativo que o projeto político cosmopolita quer justamente evitar: sob o horizonte normativo do Ocidente, o projeto político cosmopolita tende à reificação de um presente global, só que aqui não a-histórico, contra o qual tenta se precaver Beck (idem, ibidem), mas congelado nas assimetrias históricas entre West/Rest. O projeto cosmopolita de sociologia de Beck falha justamente naquilo a que se propõe, isto é: ser cosmopolita. No plano teórico, cognitivo e normativo, levar a sério uma compreensão cosmopolita da vida social significa evitar toda e qualquer restrição hermenêutica.

\section{5 - Insuficiências e desafios}

É difícil discordar do diagnóstico e da intuição teórica (transdisciplinar) de Beck. Pois se a globalização transformou de tal maneira as formas de integração social, chegando até a forçar a transformação da lógica moderna de integração da sociedade com a natureza, tornam-se relevantes questionamentos teóricos correspondentes. Todavia, nessa tentativa Beck incorre em insuficiências e contradições como as acima explicitadas. Por último, gostaríamos ainda de apontar outras insuficiências teóricas e, a partir delas e tendo em vista o falecimento repentino do autor, indicar desafios que a teoria da sociedade mundial de risco deixa em aberto para a sociologia. 
Uma primeira insuficiência diz respeito à pretendida abertura transdisciplinar. Por um lado, se Beck pode ser reconhecido por sua tentativa obstinada em fazer uso heurístico do conhecimento gerado por várias disciplinas, por outro a escolha por uma estratégia discursivo-analítica ensaísta exigiria definir com clareza o que o termo teoria significa na designação "teoria da sociedade mundial de risco". Vale dizer, temos aqui um desafio legado por Beck: seria ainda necessária uma teoria (cosmopolita?) do método, do ensaio e/ou da prática científica orientada transdisciplinarmente.

Uma segunda insuficiência diz respeito à pretensão de validade. Trata-se de saber se risco, reflexividade e cosmopolitização conseguem de fato apreender todas as dimensões da globalização, incluindo aqui também internalizações variadas da natureza conforme inflexões culturais e históricas locais. Isto é, como argumenta Costa (2006, p. 122), parece empiricamente pouco plausível que as redes de interação altamente complexas que dão materialidade para a globalização podem ser adequadamente condensadas apenas por três conceitos - risco, reflexividade e cosmopolitização. Estudos como os de Saskia Sassen (2010), Renato Ortiz (2003) e Paul Gilroy (2002) - para citar apenas alguns - sugerem a necessidade de maior ampliação temática, no sentido de incorporar outros fenômenos igualmente relevantes que caracterizam a globalização. Mas isso é pertinente conquanto se mantenha a pretensão a uma teoria geral da sociedade - como quer Beck. Caso contrário, há de limitar-se a uma teoria social (cosmopolita) do risco, a qual, mesmo assim, demandaria maior refinamento conceitual.

E aqui temos um segundo desafio deixado por Beck, voltado especificamente à designação cosmopolita pretendida em sua teoria do risco. A designação cosmopolita sugere a necessidade de fazer refletir na esfera teórica - nos conceitos de risco, reflexividade e cosmopolitização, por exemplo - a diversidade das inflexões culturais de que o risco é objeto, 
isto é, de sua manifestação como práxis culturalmente localizada na medida em que circula globalmente. Ao circularem globalmente, fenômenos como o risco conectam-se a condições históricas, culturais, políticas e ambientais diversas, exigindo um esforço maior de diferenciação conceitual à luz do escrutínio empírico. Com isso, sugere-se aqui que o risco não promove apenas um cosmopolitismo, mas cosmopolitismos, no plural, no sentido de diversificação simbólica e material específica das realidades onde se faz presente, onde motiva a ação. Em outras palavras, é preciso ainda incrementar a teoria da sociedade mundial de risco com diferenciações conceituais derivadas de estudos empíricos de realidades como, por exemplo, a brasileira.

Por fim, há uma terceira insuficiência no plano lógico, que decorre da contradição interna entre a fundação no cosmopolitismo metodológico e o diagnóstico de época. Como vimos, a contradição interna reside no fato de que, ancorado em uma trajetória histórica específica, o cosmopolitismo dos riscos globais possui um direcionamento de viés hermenêutico unilateral - do Ocidente para o mundo -, não refletindo adequadamente sua orientação metodológica para uma trans-historicidade vinculada à territorialidade. Consequentemente, opera-se uma restrição do horizonte normativo da sociedade mundial aos dilemas circunscritos por um locus histórico europeu/ocidental, impedindo de abrir a sociologia para a cosmopolitização da sociedade e da história. Com isso, sugere-se que a teoria da sociedade mundial de risco ainda necessita ser aberta desde dentro, no sentido de uma hermenêutica histórica do risco, da reflexividade e da cosmopolitização. Trajetórias históricas distintas não impedem, evidentemente, que um mesmo fenômeno, como o risco ou as mudanças climáticas, por exemplo, circule globalmente, mas sugerem que a expressão desse fenômeno como práxis seja mediada por esferas culturais diversas, conforme a localidade onde se faz presente. 
O êxito da teoria da sociedade mundial de risco consiste em ter aberto caminhos novos para o tratamento sociológico de uma intuição amplamente compartilhada nos dias atuais - a intuição de que se faz necessário reatualizar o aparato teórico-metodológico da sociologia para endereçar o particular e o universal no contexto da globalização. Essa difícil tarefa foi empreendida por Beck, todavia, sob o pano de fundo de uma concepção de modernização epistemicamente autorreferenciada (Costa e Bhambra) e sob uma interpretação autossuficiente, endógena, esquemática e "presentista" da modernidade e da história do Estado-nação (Fine e Chernilo). Uma hermenêutica do risco, da reflexividade e da cosmopolitização, no sentido da constituição da esfera pública (Kögler, 2011), da consciência histórica e da experiência (Gadamer, 1975; 1999, p. 400 sq.), permitiria, por exemplo, endereçar perguntas da sociedade mundial de risco de modo distinto: de que maneira a encenação social e as relações de definição que materializam o risco se introduzem nas relações assimétricas mundiais? De que maneira formas históricas de reflexividade caracterizam cosmopolitismos do risco diversos? Em que medida riscos globais se diversificam qualitativamente e são percebidos, definidos e geridos em regiões diversas? E num sentido fundamental: de que maneira o entrelaçamento trans-local de significações do risco promove cosmopolitizações que induzem a internalizações reflexivas variadas da natureza? Esses questionamentos sugerem um terceiro desafio: elaborar uma hermenêutica do risco, da reflexividade e da cosmopolitização, de modo a fazer valer o cosmopolitismo que a sociedade mundial de risco reivindica como fundação teórica.

Estevão Bosco é mestre em sociologia pela Universidade Estadual de Campinas (UNICAMP) e doutorando em sociologia na mesma universidade. O pesquisador possui financiamento da Fundação de Amparo à Pesquisa do Estado de São Paulo (FAPESP). $\$ estevaobosco@gmail.com. 
Leila Ferreira é professora titular do Departamento de Sociologia da Universidade Estadual de Campinas (UNICAMP). \leilacf@unicamp.br.

\section{Referências}

1. ADAM, B.; BECK, U.; LOON, J. (eds.) The Risk Society and Beyond: Critical Issues for Social Theory. London: SAGE, 2000.

2. ALLAN, S.; ADAM, B.; CARTER, C. (eds.) Environmental risks and the media. London: Routledge, 1999.

3. BECK, U. A reinvenção da política: rumo a uma teoria da modernização reflexiva. In: BECK, U.; GIDDENS, A.; LASH, S. Modernização reflexiva: política, tradição e estética na ordem social moderna. São Paulo: Editora UNESP, 1997. pp. 11-72.

4. BECK, U. The cosmopolitan perspective: sociology of the second age of modernity. British Journal of Sociology, v. 51, n. 1, 2000, p. 79-105.

5. BECK, U. La société du risque : Sur la voie d'une autre modernité. Paris: Editions Flammarion, 2001.

6. BECK, U. La sociedad del riesgo global. Madrid: Siglo XXI España Editores, 2002a.

7. BECK, U. Liberdade ou capitalismo. São Paulo: Editora Unesp, 2002b.

8. BECK, U. Understanding the real Europe. Dissent, 2003, p. 32-38.

9. BECK, U. Qu'est-ce-que le cosmopolitisme ? Paris : Éditions Alto Aubier, 2006.

10. BECK, U. La sociedad del riesgo mundial: En busca de la seguridad perdida. Barcelona: Paidós Editorial, 2008.

11. BECK, U. A política na sociedade de risco. Revista Ideias, v. 2, n. 1 (nova série), Campinas, 2010, pp. 230-252.

12. BECK, U. Cosmopolitanism as imagined communities of global risk. American Behavioral Scientist, SAGE London, Oct. n. 55, 2011, pp. 1346-1361.

13. BECK, U. Methodological Cosmopolitanism - In the Laboratory of Climate Change. 2012. Disponível em: http://www.ulrichbeck.net-build.net/index. php?page $=$ research-2. Acesso em 10 de jan. 2014.

14. BECK, U.; BECK-GERNSHEIM, E. Individualization: institutionalized individualism and its social and political consequences. London : SAGE Publications, 2002. 
15. BECK, U.; BECK-GERNSHEIM, E. Generación global. Barcelona : Paidós, 2008.

16. BECK, U.; SZNAIDER, N. Unpacking cosmopolitanism for the social sciences: a research agenda. The British Journal of Sociology, v. 57, n. 1, 2006, p. 01-23.

17. BHAMBRA, G. Cosmopolitanism and post-colonial critique. In: ROVISCO, M.; NOWICKA, M. (ed.). The Ashgate Companion to Cosmopolitanism. Farnham: Ashgate Publishing Limited, 2011. pp. 313-28.

18. BOSCO, Estevão. Sociedade de risco. In: DI GIOVANNI, Geraldo; NOGUEIRA, Marco Aurélio. Dicionário de Políticas Públicas. São Paulo: FUNDAP e Imprensa Oficial do Estado de São Paulo, 2013. pp. 471-473.

19. BOSCO, Estevão. Sociedade de risco: introdução à sociologia cosmopolita do risco de Ulrich Beck. São Paulo: Annablume \& FAPESP, 2016 (no prelo).

20. CHERNILO, D. Social's Theory methodological nationalism: myth and reality. European Journal of Social Theory, SAGE London, v. 9, n. 1, 2006, p. 05-22.

21. CONRAD, S.; RANDERIA, S. Einleitung : Geteilte Geschichten - Europa in eine postkolonialen Welt. In: CONRAD, S.; RANDERIA, S.. Jenseits von Eurozentrismus: postkolonialen Perspektiven in der Geschichts- und Kulturwissenschaften. Frankfurt am Main: Campus Verlag, 2002. pp. 09-49.

22. COSTA, S. Dois Atlânticos. Teoria Social, anti-racismo, cosmopolitismo. Belo Horizonte: UFMG, 2006.

23. DI GIULIO, G. M. Risco, ambiente e saúde: um debate sobre comunicação e governança do risco em áreas contaminadas. São Paulo: Annablume \& Fapesp, 2012.

24. FERREIRA, L. C. Idéias para uma sociologia da questão ambiental no Brasil. São Paulo: Annablume, 2006.

25. FINE, R. Cosmopolitanism. London: Routledge, 2007.

26. GADAMER, H.-G. The Problem of Historical Consciousness. Graduate Faculty Philosophy Journal, v.5, n.1, 1975. pp. 8-52.

27. GADAMER, H.-G. Verdade e método I: esboço de uma hermenêutica filosófica. Petrópolis: Editora Vozes, 1999.

28. GIDWANI, V.; SIVARAMAKRISHNAN, K. Circular migration and rural cosmopolitanism in India. Contributions to Indian Sociology, n. 37, 2003. pp. 339367.

29. GILROY, P. The black atlantic: modernity and double consciousness. London: Verso, 2002. 
30. GLYNN, K.; CUPPLES, J. Indigenous MediaSpace and the Production of (Trans)locality on Nicaragua's Mosquito Coast. Television \& New Media, n. 12, v. 2, 2010, pp. 101-135.

31. GUIVANT, J. Reflexividade na sociedade de risco: conflitos entre leigos e peritos sobre os agrotóxicos. In: HERCULANO, S.; PORTO, M. F. S.; FREITAS, C. M. (org.). Qualidade de Vida \& Riscos Ambientais. Niterói: EdUFF, 2000, pp. 281-303.

32. IANNI, A.M.Z. Choque antropológico e o sujeito contemporâneo - Ulrich Beck entre a ecologia, a sociologia e a política. Sociologias,v.14,n.30,p.364-380, 2012

33. KÖGLER, H.-H. (2011), Hermeneutic Cosmopolitanism, or: Toward a cosmopolitan public sphere. In: ROVISCO, M.; NOWICKA, M. (eds.). The Ashgate Companion to Cosmopolitanism. Farnham: Ashgate Publishing Limited, 2011.

34. LATOUR, B. Is Re-modernization Occurring - And If So, How to Prove It? A Commentary on Ulrich Beck. Theory, Culture \& Society, April, vol. 20, n. 2, 2003. pp. 35-48.

35. MYTHEN, G. Ulrich Beck: a critical introduction to the risk society. London: Pluto Press, 2004.

36. ORTIZ, R. Mundialização e cultura. São Paulo: Brasiliense, 2003.

37. SASSEN, S. Sociologia da globalização. Porto Alegre: Artmed, 2010.

38. TAVOLARO, S. B. Freyre, Damatta e o lugar da natureza na "singularidade brasileira". Lua Nova, São Paulo, n. 83, 2011, pp. 217-257.

39. VANDENBERGHE, F. Introduction à la sociologie (cosmo)politique du risque d'Ulrich Beck. Revue du MAUSS, v. 1, n. 17, 2001, p. 25-39.

Recebido em: 15/04/2015

Aceite Final: 02/09/2015 